\title{
MAKING THE MOST OF THE EU INTERNAL MOBILITY - ROMANIAN CITIZENS' MIGRATION TO THE UK IN THE CONTEXT OF BREXIT, A RACE AGAINST TIME1
}

\author{
Andrada Maria PETRACHE \\ "Spiru Haret" Researcher and PhD Candidate at the National University of \\ Political Studies and Public Administration \\ Bucharest/ Romania \\ andradapetrache25@gmail.com
}

\begin{abstract}
This exploratory study looks at the post-Brexit Referendum Romanian migration to the UK and analyses it as an outstanding case, in contrast to its overall umbrella EU27 migration, which is declining. It tries to offer in-depth explanations for why the Romanian migration is increasing in an apparent disregard for the uncertainty around Brexit and post-Brexit citizens' rights, which are yet to be agreed as the fourth deadline of 31 January 2020 approaches. It starts by considering the relevant literature and the latest statistical reports which highlight the economic reasons as the main determinants of this migration, then uses a qualitative analysis of interviews to offers more specific explanations for the individual decisions to migrate, even in the uncertain, postReferendum context. It finds that the decision to migrate is best described as a race against time in relation to Brexit, with Romanians being determined to make the most of what the UK has to offer, while legal conditions still allow it. It also highlights that Romanians have less regard for Brexit-related challenges and more interest in the academic and economic opportunities in the UK.
\end{abstract}

1 This work was supported by the UEFISCDI and SNSPA under Grant PN-III-P1-1.1-BSH2-2016-0005. 


\section{Keywords}

Brexit; citizens' rights; EU internal mobility; migration; Romanian diaspora

\section{INTRODUCTION}

The past five years have seen the European Union going through challenging times (Dinan et al. 2017, 22), from the migrant crisis to the rise of populism and illiberalism across some member states or the emergence of new national parties that are rearranging the balance of power in Brussels and the vision for Europe. But while there could still be some debate on the afore mentioned challenges, there is a particular one that will certainly make it into the history books: the first departure of a member state. The UK's decision to leave the EU has been influencing EU politics in a multitude of ways ever since the Referendum on 23 June 2016, from driving the agenda at European Councils to complicating the seat distribution in the 2019 elected European Parliament. There is one particular topic that has been a constant priority throughout the negotiations between the UK and the EU and that is citizens' rights - the future status of those EU27 and British citizens who used their EU right to free movement to make another member state their home.

EU statistics show that internal mobility ("the free movement of EU citizens who can live, work, study and do business anywhere in the EU") is what Europeans value most out of the EU's achievements and priorities (Eurobarometer 2018, 29). And it is precisely this freedom of movement that the UK authorities are considering ending on day one post-Brexit (Politico 2019). The status and rights of those who have already migrated, be them EU citizens in the UK or British citizens in EU27, and the post-Brexit conditions for EU27-UK mobility have been a priority chapter in the negotiations and have held the front page of European newspapers ever since the vote in June 2016. But while several offers have been put forward, including the UK Government's EU Settlement Scheme for the 3 million EU27 citizens living in the UK, their future and the post-Brexit migration conditions remain under uncertainty. 
In this context, the EU27 have registered a decrease in migration towards the UK after the 2016 Brexit Referendum, with EU migration towards the UK reaching its lowest level since 2013 (ONS 2018, 8; ONS 2019, 5). However, the Romanian case presents itself as an atypical one, going against time and against the European trend, as the Romanians have overpassed the Irish and became the second largest non-British nationality group in the UK in 2017 (ONS 2017, 6-7). As the Office for National Statistics states in the report, "The largest increase for an individual country between 2016 and 2017 was seen for those born in Romania, and those with Romanian nationality'(ONS 2017, 6). Romanians have thus continued the upsurge in migration flows which began following the lift of working restrictions in 2014, despite the uncertainty, anxiety and even discrimination so-often quoted in the public discourse.

This paper starts from the afore mentioned statistics and seeks to explore whether and how Brexit impacted migration to the UK. It explains the reasoning behind Romanian citizens' attraction for internal mobility, with a focus on the unforeseen attraction of the UK, in the detriment of other EU member states, even in the context of Brexit. It therefore treats the Romanian positive migration as a case study, which has been described by official data as atypical in the European context and which seems to have defied all official expectations (whether we are talking about the Romanian, British or European authorities), who were forecasting a decrease in the number of Romanian migrants in the UK in the uncertain context created by the Brexit negotiations. To this purpose, the paper seeks to identify the various individual reasons, as well as to contour a general pattern that convinced so many Romanians to leave their status quo and migrate towards the UK.

\section{LITERATURE REVIEW}

2.1. Understanding post-Brexit Romanian migration towards the UK

Diaspora has been at the forefront of Brexit negotiations due the special importance given to the citizens' rights chapter. Citizens' rights (of both EU27 living in the UK and British living in EU27) has been a priority topic and area of 
negotiation which needed constant attention and reassurance, as the two negotiating parties (EU-UK) were redesigning the framework for the UK's exit from the EU and for the future relationship.

In Romania, diaspora has been a key theme on the national public agenda ever since the country's accession to the EU, when intra-EU mobility allowed for the establishment of important Romanian communities in Italy, Spain, Germany or the UK (OECD 2019). Although not the largest Romanian diaspora in the EU, the Romanian diaspora in the UK has been constantly in the spotlight for the past years, due to Brexit and its associated campaigns and negotiations, both pre and post Referendum.

The Romanian diaspora, although a highly fragmented (Sinatti 2015) "imagined community" (Anderson 1983), is an entity that claims many requests in its name, made both by its members and by the Romanian political actors. There is much debate about the responsibility a home country has towards its diaspora, from setting up dedicated institutions (Ragazzi 2009, 390) to securing their rights under the "politics of belonging" (Yuval-Davis 2016, 213). Whether higher or lower, there is definitely a certain level of responsibility that the home state shares for its citizens who are living abroad (Østergaard-Nielsen 2003, 221).

So one ought not to be surprised by the Romanian authorities' involvement, alongside the British and European, in communication campaigns and events tackling the future status of the Romanian citizens in the UK. The Romanian Embassy in London, for instance, has already organised several series of Q\&A sessions for the Romanian community in the UK, whether independently or in collaboration with the British Foreign and Commonwealth Office, between 2017 and 2019. Nor is one to be surprised by the common front that the Romanian authorities have demonstrated on this topic from 2016 onwards (despite serious divergences and almost no dialogue on other political topics, be them domestic or foreign) and by their decision to push for this as a priority topic within the negotiations from the very beginning.

This is the context in which the paper seeks explanations for the migration flow, by employing various explanations from the relevant literature, be them economic, political, personal, or maybe even connected to the British "soft power" (appeal through language, culture, history) (Nye 2004). A particularly 
interesting feature of this migration is given by the uncertain context in which the Romanian decided to migrate towards the UK: the 2017 agreement on citizens' rights was included in the Withdrawal Agreement, but failed to offer full certainty, as even before being rejected by the British Parliament, it was still laying under the caveat that "nothing is agreed until everything is agreed". Not to mention the constant talk about a no deal scenario throughout the two years of negotiations with the EU and the subsequent extensions, which only intensified as the product of these negotiations, the Withdrawal Agreement, in its various forms, was rejected by the British Parliament on numerous occasions.

\subsection{The Romanian Diaspora: a global and UK-focused view}

The Romanian diaspora is the fifth largest in the world and amounted to 5,6 million people on 24 July 2019 according to an OECD study commissioned by the Romanian Ministry of Foreign Affairs. This figure does not include the historical communities, which increase the number of Romanians living beyond the national borders to 9,7 million. According to the study, the Romanians who have emigrated to another EU member states following Romania's accession to the EU (2007) constitute most of the diaspora.

The top destination countries for Romanian migrants in 2015/2016 were Italy, Germany, Spain, United Kingdom and the United States. At that time, and prior to the Brexit vote, the Romanian diaspora in the UK amounted to 224600 migrants (OECD 2019). The current figure used by authorities is of approximately 411 000, which means that the Romanian diaspora in the UK has doubled in the last three years, despite Brexit and its surrounding uncertainty. In terms of geographical distribution in the UK, in 2016, $40 \%$ of the Romanian diaspora was concentrated in the Greater London region. Important communities were also living in the South East and East Midlands regions and OECD claims that the tendency is for the Romanian population to generally reside in England. However, small communities were also present in Wales, Scotland and Northern Ireland. 
The afore mentioned study shows that most respondents left Romania for economic reasons (which vary from low wages, lack of employment opportunities or poor infrastructure), although a disappointment with the Romanian political class and corruption are also mentioned. The OECD report shows employment (whether with or without a job prior to migrating) as the main reason for which $75 \%$ of Romanians in the UK decided to emigrate from Romania. The current paper will build on that and offer more insight on the individual reasons why Romanians chose to migrate and to opt for the UK during such turbulent times for the British politics and society.

The emigration intentions remain high, with over a fourth of Romanians expressing willingness to settle abroad, should an opportunity arise. The situation is even worse for the Romanian youth, with almost half of the 15-24 segment stating their intention to emigrate. OECD links this to poor job prospects in Romania, especially for those with higher education, which justifies this paper's neoclassical approach on this particular migration case study.

\subsection{Diaspora through the lenses of the migration theories}

Migration is a constant given in nowadays globalised and modern society, as people change countries and continents in search for prosperity, professional fulfilment or their own version of happiness. It is even more visible and essential inside the EU, where citizens regard the free access to internal mobility as the greatest accomplishment of the Union (Eurobarometer 2018, 29), an organisation which professionals would rather praise for its success in maintaining peace on the old continent.

Ravenstein's classical migration theory can no longer fully account for modern migration, as the current situation rather deviates from, than adheres to his outlined rules (Ravenstein 1885, 198-199). Migration remains highly ageselective and economic reasons still play a crucial role, but distance no longer dictates the migration destination - as outlined previously, the fifth largest Romanian diaspora is in the US, while the first four seem to be better explained in connection to economic opportunities than through distance. 
Migration no longer proceeds step by step - there are tens of villages in Romania mainly inhabited by children and grandparents, as the working age population has migrated to Western Europe. Their migration was not hierarchical - these migrants did not move to the nearest town, then to Bucharest and only after to a main European capital. They went directly for the latter.

Therefore, the current study uses the neoclassical theory of migration as a starting point (Harris and Todaro 1970; Sjaadstad 1962; Massey et al. 1993), treating the economic factor as the main determinant and aligning itself with the migration research conducted around the last EU enlargements (Bauer and Zimmermann 1999). Under the neoclassical theory, "migration is stimulated primarily by rational economic considerations of relative benefits and costs mostly financial but also psychological", where the individual decision to migrate is dependent on the expected outcome rather than the actual one. (Todaro and Smith 2014, 362)

But the same neoclassical theory also drops the idea of full employment at destination and considers the probability of employment in the destination country as main determinant of the decision to migrate, alongside wage differentials. This addition was introduced to account for migration towards overpopulated urban regions, where jobs may be scarce, but which still remain popular, as the migrant weighs the probability, not the actual employment. (Bauer and Zimmermann 1999; Harris and Todaro 1970). If we are to apply the model to the analysed case study, the expected outcome is constructed through the interaction of two variables: the wage differential between the home country, Romania, and the destination country, UK, and the probability of finding the expected employment in the UK.

Migration is thus triggered by the wage differences between the sending (labour-rich) and receiving country (capital-rich) (Harris and Todaro 1970). Empirically, this would translate into the poorest countries being the main sources of migration. In fact, critical adjustments to the neoclassical theory have brought into discussion the idea of affording to fund migration and have shown that a growth in a state's wealth initially encourages migration, as more people 
are able to afford it, with migration only starting to decrease as the development continues in that sending state (de Haas, 2008; Faist, 2000; Kurekova, 2011).

The idea that it is not the poorest countries that send most labour and that Romania had had to reach a certain level of political and economic development in order to enter the EU in 2007, combined with the granting of the EU right of free movement and access to the labour market to Romanian citizens could explain the previously described picture of the large Romanian diaspora. But analysed at micro-level, the existence of this diaspora could be explained by individual choices, thus employing the human capital theory of migration (Sjaadstad 1962).

Sjaadstad's theory tries to account for migration by employing the micro-level socio-demographic characteristics of an individual, such as occupation, skills, age, gender, marital status or preferences. All these should play an important role in an individual's success in the host country: highly skilled, higher educated or younger people being, therefore, advantaged.

However, the neoclassical theory of migration does not go as far as accounting for the conditions and appeal of home and host states or for the role national politics play in the individual's decision. It does not consider national specificities and variables, such as the effects produced by a change in the politics regime, which are essential for the case study of a former-communist, Eastern European country like Romania.

\subsection{EU Free Movement in Brexit UK}

The previous arguments might account for Romanians' desire to emigrate, but why did they choose the UK? The latest report issued by the Office for National Statistics shows that "work and study remain the most common reasons to move to the UK" (ONS 2019, 6). In fact, study migration might have "narrowly overtaken work as the main reason for immigration" in the past year (ONS 2019, 7), although it is still to early to tell whether it will replace work as the main determinant of migration. This statistical data further demonstrates what the migration theories were suggesting, that migration is primarily economic. 
Yet how does the host country see this migration? Migration has been a salient topic during the pre-Referendum Brexit campaign and remained a highly debated one throughout the negotiations, with the British Government keen to stop (in the case of a hard-Brexit) or at least contain (in the event of a soft-Brexit) immigration. One could even argue that the "fall in EU migration" (ONS 2019, 5 ) is linked to the political and mediatic campaign around Brexit and the uncertainty surrounding it. The UK Government might have hesitated on the substance, but it has been continuously clear on the idea that the Brexit vote will be interpreted as a "mandate for controlling immigration and withdrawing from the deep regulatory integration of the Single Market" (Sampson 2017, 180).

Understanding the vote to leave the EU and the reluctance towards immigration is key, as it encompasses several explanations for the current attitude towards negotiations for future migration policies, the status granted to the 3 million EU citizens living in the UK and to Brexit itself. Immigration seems to have "played a substantial role in the campaign, especially in England and Wales, alongside concerns about sovereignty ('taking back control')", but the influencer seems to have been a "fear of immigration" rather than the actual immigration (Shaw 2016, 101). Perceptions depended on the level of diversity and multiculturality surrounding the individual, with large urban centres voting to remain.

The roots of the problem are complex, with two of them being particularly relevant for the current study. The political discourse on migration in the UK has "for some time elided any 'moral' differential between free movement and immigration from third countries (and between labour migration and asylum seeking)" (Shaw 2016, 101). This lack of differentiation was combined with the fact that UK's legal commitments to the EU treaties forbid it from being able to limit numbers or select the migrants from the other EU member states, who were under the protection of EU right of free movement. This resulted in EU27 migrants becoming scapegoats and targets of hostility from "older white working class communities" who were feeling economically and culturally left behind by globalisation (Shaw 2016, 101).

The second, which had the biggest effect on the Romanian and Bulgarian migrants, begins with the 2004 Eastern EU enlargement, when, unlike other 
member states, the UK opened its borders without a transitory period with work restrictions in place. The effect was a large-scale migration towards the UK from the new member states, most notably Poland, which was supposed to offer supply for low skilled labour from another source than the traditional Bangladesh and Pakistan. But the migratory reality went beyond the expectations and estimations of the British government, "pushed immigration to the top of the agenda" and fuelled the idea that future migration flows were impossible to forecast. This idea will be at the core of future heated debates about the scale of migration that would follow the lifting of the work restrictions for Romanians and Bulgarians in 2014 (D'Angelo 2017, 175-178; Galgoczi, Leschke and Watt 2012, 1).

This is the context in which EU migration, and therefore, EU free movement, were portrayed in British tabloids as taking the form of 'floods' or 'invasions' of migrants from Eastern Europe (Fox et al. 2012; D'Angelo 2017). The topic polarised the British society, "with those who were educated being more comfortable with immigration compared to those with little education" (D'Angelo 2017, 187), a divide that became crystal clear with the results of the 2016 Brexit Referendum.

Exposed to such literature, one cannot but wonder whether and if yes, how these policies and discourses translate into the real-life experience of Romanian migrants. The curiosity is further fuelled by the fact that some of these migrants moved to the UK in this previously depicted polarised context, manifesting an apparent disregard for it. This is why the second part of the study uses qualitative analysis of interviews to understand the determinants of this migration trend and the real-life applications of the literature.

\section{METHODOLOGY}

This research started from British Office for National Statistics data showing an increase in Romanian migration to the UK, despite Brexit and the overall EU migration to the UK manifesting a tendency of decline. The aim was to understand if Brexit had any role in this migration and if so, to offer more 
explanations about that role. Were the Romanians who migrated to the UK after the Referendum in 2016 worried about Brexit? What were they worried about, more specifically? What convinced them to migrate to the UK during this rather uncertain and volatile context? The hypothesis is that Brexit played the role of a migration trigger for the Romanians who wanted to make use of EU internal mobility and migrate to the UK while the legal framework still allowed it.

I expected Brexit to have little influence on the decision to migrate, a scenario that would justify the Romanians' popular choice of migrating to the UK in large numbers. So popular, that they finally surpassed the Irish and became the second largest non-British nationality group in the UK after the Poles. But why were Romanians not discouraged by Brexit? How come they were not influenced by the lack of certainty with regards to their future? The study uses an exploratory approach to extend the knowledge on the motivations behind this particular case of Romanian migration to the UK in the context of Brexit, while also providing insights for the general motivations behind the popularity of EU internal mobility overall.

Moreover, I was further interested in discovering the elements that provided certainty to the Romanian migrants and the factors shaping the migration intentions. The afore-quoted literature suggests that migration is primarily economic, so I wanted to see whether this was indeed the main determinant and if yes, why was the UK preferred to other destinations. Did other factors such as British soft power or the existence of an already significant Romanian diaspora (friends and family reunification) also play a role? I also looked at their willingness to remain, thus distinguishing between short, medium and longterm migration, interest for onward migration, as well as their willingness to return to Romania. All with the aim of understanding the different types of motivations and the equally various plans in the UK - short or medium term, goal oriented etc.

In order to confirm the hypothesis, the research makes use of qualitative online interviews to test the theoretical framework and identify both general and specific reasons that determined the respondents to migrate towards the UK even in a volatile context from a citizens' rights perspective. Semi-structured, video interviews have been conducted between 13-23 August 2019 with a 
convenience and snowball sample of 10 Romanians who have migrated to the UK after June 2016. The sample was a convenience and snowball one, consisting of 10 Romanians aged 20-30, who have moved to UK in 2016, 2017, 2018 and 2019, 6 men and 4 women, with or in the process of obtaining an academic degree, living in diverse communities ranging from urban multicultural areas such as London, Leeds or Nottingham to small university centres such as Cambridge or Newport and with varied areas of study or activity: IT, Transport, Consultancy, Law, Psychology, Physics or Food Safety.

The chosen research method was a semi-structured open interview, conducted via video calls of approximately 20 minutes. Methodologically, the interview transcripts were subject to thematic analysis and Atlas.ti was used to code and facilitate the analysis of the text data. Since the sample is unrepresentative from a statistical point of view, the results are difficult to generalise. However, in addition to the literature mentioned in the first part of the study, they bring valuable insight to this exploratory study and can serve as a starting point for future research on the reasons behind Romanian migration to the UK in the context of Brexit.

The themes that were followed throughout the interviews were: determinants of migration (economic, academic, personal-friends and family, political factors), the particular appeal of the UK (prosperity, soft power, open society), Brexit effects on the day-to-day life of Romanian migrants. In order to understand whether any of these themes are more or less relevant depending on the migrants' initial intentions, I also looked at the willingness to remain, return or interest for onward migration.

\section{FINDINGS: THE ROMANIAN MIGRANTS' EXPERIENCE}

\subsection{Reasons to migrate}

There are three categories of factors mentioned by the respondents as their motivation to move to the UK, even in the context of the UK's decision to leave the EU. The main one is represented by academic and economic opportunities, 
with their variations and specificities: 'I wanted to go to university there. And my parents had just lost their jobs in Romania, [...] so we all left' or 'I received a really good offer on LinkedIN, but I had been considering going to the UK for a long time, for experience, a plus in my $C V$ and for economic reasons'. This finding aligns to the results of the ONS study, which was highlighting study and work as the main determinants of migration towards the UK.

The students who were interviewed appreciate the variety of academic programmes in the UK, including double degrees, that allow them to specialise in niche areas that are not available in other countries. Romanian students also seem to have a high regard for the professional prospects UK programmes offer after graduation, both in the UK and outside of it. Examples include specialising in Common Law and then being able to work on international financial transactions, all settled under the Common Law framework ('It's a very international environment [...] I have career opportunities that I wouldn't have been able to have anywhere else'), finding a more applied programme to study Psychology under a Business Psychology degree or simply striving for excellence in one's chosen field of study at one of UK's great university such as Cambridge or King's College London.

From the participants' answers, having an offer or a contract for the period of the study also worked as an insurance policy against Brexit uncertainty, as the terms were clear that once they started studying under certain conditions and fees, they would be able to continue in the same manner until graduation. Therefore, in the case of study migration, it could be argued that participants wanted to make the most of the opportunities created by the EU, while they were still available - as demonstrated by some responses admitting concern for any changes that could have affected the students' status, both before and after the moment of migration: 'Every year I would wait for news about the status of the EU students and about how Brexit could affect it.'

The case of work migration is very similar, with Romanians appreciating the job offer in the UK, the ease with which one can find a job (for those who were unemployed in Romania), the level of wages and the added value in terms of professional experience offered (for those who were looking for the next step in their career). In fact, since many of those who went to the UK to study also 
expressed interest and satisfaction with the employment prospects the UK has to offer, the economic aspect seems to be the main trigger of this migration. And it presents itself as one that does not disappoint, with testimonials reading: 'The financial aspect was my main motivation' and 'I always wanted to be an independent person, who doesn't rely on her parents and I was able to that in the UK, including to save money for university'.

The second most common category seem to be the existence of an already significant Romanian diaspora, understood as personal reasons such as the influence of having friends or/and family in the destination country. Six respondents talked about how having friends or family in the UK contributed to them deciding to move there. Some had both, some had extended families, while others just relied on the presence of their friends, even if in some cases they were 'one hour away': 'I chose the UK because I had relatives there: uncles, aunts, cousins, who were already living here for 8-9 years', 'My father lived there for 5 years, my girlfriend was there to study, so there was no reason for me not to go'. None of the respondents talked about family reunification as a main motivation, although one mentioned how having close relatives already settled there facilitated an easier integration when the respondent and the parents moved there, to study (respondent) and work (parents). And while it wasn't the case of any of the respondents, two of them mentioned many Romanian migrants gathering in the same neighbourhoods and preferring to live slightly isolated, in ethnic communities.

The accessibility of English language was the third most mentioned reason for choosing the UK - 'England was the direction because I speak English, I had even taught English and had participated in the English language Olympics. So it was a natural choice, it was pretty much the only country that attracted me'. However, it would be hard to generalise and claim that British soft power was the umbrella factor, since one of the respondents specifically said he is not attracted by the British culture or 'tea-drinking habits'. Nevertheless, another respondent did mention her passion for 'England in one way or another and for their culture and accent', so perhaps a further quantitative analysis would be able to answer this and test whether the British soft power was one of the main factors appealing to the Romanian migrants. For now, the present study could only highlight the role 
of the language, which allowed the UK to outrank other EU countries in terms of accessibility and ease of integration.

\subsection{Moving to the UK: Expectations vs. Reality}

When asked to evaluate their experience in the UK in terms of expectations versus reality, the most popular choice amongst respondents was for in line and under. Some even talked about how realistic expectations were easier to be met: 'I was not expecting flying unicorns and for everything to be rainbows and butterflies, but I was expecting similar obstacles to those I had do deal with back home; and this is how it was'.

Those who ranked the experienced reality as being below expectations suggested the following disappointing aspects: prices and wage levels ('The wage level and societal development are beneath my expectations'; 'I was negatively impressed by how expensive the rent is'), societal development and the attitude and education of the British people ('I feel like the British are quite cold'; 'I think I had a cultural shock, on the basis of my preconceptions about them.[...]When you have to deal with less educated people, you'd be surprised by their quality'), crime rates ('Crime rates are higher than in Romania. London is not just Oxford and Regent Street and Hampstead. London is Brixton, Hackney, Peckham, Stratford, one cannot live in over three quarters of London.'), the public health system ('I know a lot of people who had to wait 4-5 months for a doctor's appointment'), 'transport infrastructure outside of London', the level of stress in the British society (especially in London: 'I expected life to be easier and it wasn't. I expected to be less stressed and I am not.'), as well as 'the level of corruption'. Some respondents blamed the media for their high expectations which proved to be unrealistic 'I realised that all I knew about West European countries was in fact just media disinformation'.

However, on a more positive note, Romanians seem to be highly appreciative of the opportunities the UK has to offer, be them academic, professional or financial: 'I was not expecting this many possibilities. Whatever you want to do, no matter how obscured or niche, you will find an opportunity in London'. And some also appreciate the British society for being highly open and tolerant: 'The level of 
development, openness and tolerance in the society is exceeding my expectations'. This openness seems to be a topic to be debated, however, as one respondent listed this as a strong point, while another saw it as a disappointment.

The integration process was fairly easy for the respondents, as seven out of ten have reported: 'It's very easy to build yourself a life here'. The main facilitators seem to have been the people, who are very 'polite, nice and sociable', the dynamic job market and easy access to employment, but also the personality traits of those interviewed, as some described themselves as 'sociable'. Those who found it harder to integrate reported going through several changes and hence making a more extreme exit out of their comfort zone ('I went out of my comfort zone on so many levels. All I had to do was change my family and girlfriend and I would've had a different identity' or having been too focused on their studies ('The first year and a half was difficult, it was hard for me to adapt. I was spending most of my time in my room, studying, focused on the idea that I wasn't there to waste time').

\subsection{Decision to migrate towards the UK in the context of Brexit}

Brexit seems to have had no or very little influence in the respondents' decision to migrate towards the UK. Some (three of those interviewed) were completely unaware of the prospect of Brexit before it happened: 'I had no idea about Brexit'; 'I was shocked. I had no idea about what was going on, about the vote. A friend called to tell me that the UK is leaving the EU and I said 'How come?', because I had tickets'. Others had their plans made and were either under pre-signed educational and work contracts or with no intention of remaining in the UK for more than 2-3 years, which was the estimated timeframe for departure. This approach was perfectly summarised by one participant's quote: 'My plan was made and Brexit had zero influence'.

They also said that Brexit had in fact 'rushed' their decision to migrate, as many saw the 2-3 years envisioned for negotiations as enough time for them to fulfil their plans in the UK. As some respondent put it, 'I knew from even before I moved to the UK that even in case of a no deal, I would still have 2 years and no intention of staying beyond that'; 'It rushed it. I wasn't worried at all, I did not care at all. What 
could they have done to me? Send me home. I could go to some other country, there was no arduous desire for me to stay here. When I left, I knew that I would only be gone for a short period of time, 2-4 years.'. Some respondents reported that they did not even care about Brexit until recently, when the deadlines started to approach: 'At first, I did not care about it, because there was still a lot of time left until the deadline. [...] I was thinking that until March 2019, I'm not going to look and I'm not going to care'.

One could thus argue that migration after the 2016 Referendum was, in fact, a race against time, a period during which Romanians could 'still go': 'We thought that 'we can still go', not that it is a deadline that would limit us from staying as long as we had planned'. In support of this interpretation, one of the respondents even spoke about a possible new wave of migrants who come to the UK in the upcoming months, to take advantage of the period before the actual departure from the EU, during which they still have free access to the UK and are still eligible to apply for Pre-Settled Status 'I actually expect a new wave of people coming to apply for pre-settled status'.

\subsection{Experienced Brexit}

Brexit had little influence on the decision to move to the UK and it seems to have had comparably little impact on the lives of some Romanians, who have reported 'no effect' on normal citizens who are focused on their job and do not get influenced by bombastic, inflating pieces of news, either in the Romanian or British media (Cheregi 2015, 12-14).

However, some respondents spoke about a series of negative effects of Brexit that are already visible: economic impact, social unrest, uncertainty or fatigue. In terms of economic impact, respondents mentioned the devaluation of the pound, which is a disadvantage for the Romanians who 'get their salary in GBP and then exchange it into RON when returning to Romania'. An increase in certain prices is another negative effect highlighted by one of the respondents.

Respondents also mentioned various levels of social unrest around Brexit, from a constant preoccupation and concern about the topic in both private and public life, to protests and even up to an 'increase in the number of crimes committed out of 
lack of tolerance'. Uncertainty is another aspect mentioned several times and even described by one of the respondents as being the object of 'public consensus'. One Romanian student reported a constant preoccupation with how Brexit might affect the status of European students, while another respondent talked about the public perceiving Brexit as tragic and disastrous.

Those who participated in the study confirmed the existence of a Brexit fatigue, explained either by citizens' personal preoccupations and problems or by the dissatisfaction with Brexit stealing the spotlight and 'diverting the attention from other issues, such as the health system'. What is even more interesting is that this Brexit fatigue is reportedly experienced across the spectrum, amongst both Leavers and Remainers.

Then there are those who do not even think that Brexit is going to happen. Two of the respondents quoted the state of the recent EU-UK negotiations and the provisions of EU law as an explanation for either further extensions or the UK simply not leaving the EU at all. This could be an explanation behind migration in the context of Brexit, if, for various reasons and due to more or less informed analyses, Romanians would dismiss the prospect of the uncertainty-creating event.

\subsection{Discrimination in the context of Brexit}

Those who participated in the study have been largely lucky in experiencing no discrimination in the context of Brexit. One participant even spoke about positive discrimination for migrants, as 'many British friends told me they did not get the job because the employer was looking for diversity'. However, even if they did not report direct forms of discrimination, two respondents confirmed that some British citizens embrace the myth of 'Europeans (and especially East Europeans) coming to the UK to steal their jobs'. Sometimes, they do not even differentiate between EU and non-EU migration, as one respondent spoke about discrimination against migrants, but did not necessarily link it to Brexit, while another said that 'The majority of migrants come from non-EU countries and have British passports, but some Brits are convinced that these non-EU citizens are in the UK 
because of the EU'. This quote is a perfect illustration of the idea discussed in the literature review part, according to which careless political discourses have led to confusion in the minds of ordinary citizens, who can no longer distinguish between EU and non-EU migration (Shaw 2016).

So while it is not the case of this unrepresentative sample of Romanians who study or work in academic or highly educated environments, some forms of Brexit-related discrimination do exist. Respondents agree that it is more likely to come from less educated persons and happen in less diverse communities, thus confirming what has been indicated in the literature (Shaw 2016). Some suggest that those Romanians who choose to live a more isolated life, largely in the closed Romanian communities and those who do not have a good command of the English language are more prone to this discrimination. Those who live outside London, in smaller, less international and diverse communities, are also more likely to be exposed to it, according to one respondent.

4.6. Willingness to stay and likelihood of leaving the UK for Brexit-related reasons

Two of the respondents want to stay in the UK 'forever' and five are definitely interested in staying for another 2-5 years. Those with medium-term (3-5 years) plans have clear specific targets to achieve before leaving the UK: academic programmes to complete, special qualifications to obtain or projects to finalise at work. So do those with short-term plans ( $<2$ years), but in this case, the targets are economic, as the respondents are focused on achieving a certain threshold in savings before returning.

When asked about what would need to happen in the context of Brexit to make them want to leave the UK as soon as possible, two of the respondents have clearly stated that there is 'nothing' that would convince them to leave before fulfilling their goals (finishing studies or building a successful career). For the rest of the respondents, however, a Brexit that would have negative effects on the economy ('pound devaluation'), difficult access to jobs or an end to the free movement that is too drastic would be the deal-breakers. 
From an economic perspective, students would leave if they would lose their funding or current financial terms. Those who are already working would leave if the pound would depreciate too much or if salaries would be too small. Those in search of a job would leave if finding one would become too difficult and if they would need 'visas that are too hard to obtain' or if they would be suddenly discriminated on nationality grounds. A decrease in cultural diversity would also be a minus that could determine some Romanians to leave the UK, since this was one of the aspects they were appreciating in the British society. Lastly, for those whose job requires frequent international travel, long border controls would be the argument convincing them to opt for another country of residence, that allows frictionless freedom of movement.

\subsection{Onward and return migration}

Seven of those interviewed would at least consider, if not definitely be interested in onward migration. The most frequent destinations are Western EU member states, but there are respondents who would also consider destinations such as the US, Canada, China, Japan, Dubai or Hong Kong.

There is a similar situation for the prospect of returning to Romania, with only 3 respondents stating that they are not considering it, as they would see it a 'regress'. Four respondents are determined to come back, as their 'friends, family and entire life are in Romania'. One of them even sees the experience in the UK as revealing of 'how much he loves and appreciates Romania'. Those who are considering it with some reluctance quote a need for more opportunities that allow them to do what they enjoy ('a business idea or a job I like'), but as one of them explains 'I would not come back to Romania just because it is Romania. Familiarity is an advantage, but it not big enough to make me want to return no matter what'.

The reported intentions illustrate one of the first findings of the interview: that Brexit had almost no influence on the decision to migrate for the Romanians who had clear, time-limited plans in the UK. There was nothing for Brexit to overshadow and surround with uncertainty if that something was not here, if 
the migrants never intended to stay beyond the few years envisioned for negotiations or transitional arrangements.

\section{CONCLUSIONS}

The findings of this exploratory paper speak of a reality beyond attentionseeking headlines and explain the rationale behind what seems to be a risky, surprising decision, but is in fact a simple act of making the most of EU internal mobility. The paper does not speak of why the overall EU migration towards the UK is in decline, but it provides more insight on why the Romanian one is not. Brexit negotiations have been in a constant race against time, largely led by the postponed deadlines, and this study shows that so was the Romanian migration to the UK.

For the Romanians considering moving to the UK after June 2016, it was of lesser importance that their post-Brexit status was unclear. They were much more interested in what the UK had to offer and focused on taking advantage of the short-term possibilities before worrying about medium or long-term challenges. Some disregarded Brexit because they only intended to stay for a short period of time in the UK. Others had long-term plans, but reasoned that as long as they are there before the Brexit date, under the EU migration terms, they will be able to stick to them. Either way, all respondents seemed to have been encouraged by the fact that they could 'still go'. The results also highlight an outstanding economic appeal of the UK, which alongside an already existing Romanian diaspora and the accessibility of the English language, seems to have triggered this migration wave.

The impact of a member state's departure on the other is still unknown and various variables, including the bilateral relationship between the departing and remaining member state, need to be taken into consideration. Given the size of the Romanian diaspora in the UK, one of the greatest impacts that Brexit will have on Romania will be on and through this diaspora. Indeed, the present study has revealed that Brexit only had a small impact on the very recent, post Referendum Romanian diaspora, but the results cannot be generalised for the 
wider Romanian community in the UK, whose plans might not have been so synchronised with the deadlines of Brexit. The study therefore reveals opportunities for further research, whether focused on the post-Referendum Romanian migration to the UK or on the entire Romanian diaspora in the UK.

\section{REFERENCES}

- Anderson, Benedict. 1983. Imagined Communities: Reflections on the Origin and Spread of Nationalism, London: Verso

- Amelina, Anna; Horvath, Kenneth. 2017. "Sociology of Migration", The Cambridge Handbook of Sociology: Core Areas in Sociology and the Development of the Discipline (Volume 1). Cambridge: Cambridge University Press, pp. 455-464

- Balch, A., Balabanova, E. 2006-2013. "Ethics, politics and migration: public debates on the free movement of Romanians and Bulgarians in the UK", Politics. 36(1), pp. 19-35

- Bauer, Thomas; Zimmermann, Klaus F. 1999. "Assessment of possible migration pressure and its labor market impact following EU enlargement to Central and Eastern Europe." A study for the Department of Education and Employment, UK. IZA Research Report No.3

- Brubacker, Rogers. 2005. "The 'diaspora' diaspora", Ethnic and racial studies, 28(1), pp. 1-19

- Cheregi, Bianca-Florentina. 2015. "The media construction of identity in anti-immigration discourses: the case of Romanian immigrants in Great Britain", Romanian Journal of Sociology, (1-2), pp. 5-25

- D'angelo, Alessio; Kofman, Eleonore. 2017. “UK:Large-Scale European Migration and the Challenge to EU Free Movement", South North Migration of EU Citizens in Times of Crisis. Springer Open, pp. 175-192

- De Haas, Hein. 2008. "Migration and development. A theoretical perspective," International Migration Institute Working Paper no.9. University of Oxford 
- De Haas, Hein. 2010. "The Internal Dynamics of Migration Processes: A Theoretical Inquiry", Journal of Ethnic and Migration Studies. 36:10, pp. 15871617

- Dinan, Desmond, Nugent, Neill, Paterson, William E. 2017. The European Union in Crisis. Palgrave Macmillan

- European Commission, TF50 (2017) 19 - Commission to EU 27, 8 December 2017, "Joint report from the negotiators of the European Union and the United Kingdom Government on progress during phase 1 of negotiations under Article 50 TEU on the United Kingdom's orderly withdrawal from the European Union", https://ec.europa.eu/commission/sites/betapolitical/files/joint_report.pdf.

- European Commission, Standard Eurobarometer 90, Autumn 2018

- Fox, J., Moroșanu, L. E., \& Szilassy, E. 2012. "The racialization of the new European migration to the UK". Sociology. 46(4), pp. 680-695

- Galgoczi, Bela, Leschke, Janine, Watt, Andrew. 2012. EU Labour Migration in Troubled Times - Skills Mismatch, Return and Policy Responses. Routledge

- Harris John R., Todaro, Michael P. 1970. "Migration, Unemployment and Development: A Two-Sector Analysis". The American Economic Review. Vol. 60, No. 1, 1970, pp. 126-142

- Kurekova, Lucia. 2011. Theories of migration: Conceptual review and empirical testing in the context of the EU East-West flows, Interdisciplinary conference on Migration. Economic Change, Social Challenge, University College London

- Massey, Douglas S., Arango, J., Hugo, G., Kouaouci, A., Pellegrino, A., Taylor, J.E. 1998. Worlds in motion. Understanding international migration at the end of the millennium, Clarendon Press Oxford

- Massey, Douglas S., Arango, J., Hugo, G., Kouaouci, A., Pellegrino, A., Taylor, J.E. 1993. "Theories of International Migration: A Review and Appraisal", Population and Development Review, Vol. 19, No. 3, pp. 431-466

- Nye, Joseph S. 2004. Soft Power: The Means to Success in World Politics, Public Affairs New York 
- OECD, Talent Abroad: A Review of Romanian Emigrants, 2019, OECD Publishing, Paris, https:// doi.org/10.1787/bac53150-en.

- Office for National Statistics, Statistical bulletin:Population of the UK by Country of Birth and Nationality: 2015, https://www.ons.gov.uk/peoplepopulationandcommunity/populationan dmigration/internationalmigration/bulletins/ukpopulationbycountryofbir thandnationality/august2016

- Office for National Statistics, Living abroad: dynamics of migration between the UK and the EU2, 2017 https://www.ons.gov.uk/peoplepopulationandcommunity/populationan dmigration/internationalmigration/articles/livingabroad/dynamicsofmig rationbetweenbritainandtheeu2

- Office for National Statistics, Statistical bulletin: Population of the UK by country of birth and nationality: 2017 https://www.ons.gov.uk/peoplepopulationandcommunity/populationan dmigration/internationalmigration/bulletins/ukpopulationbycountryofbir thandnationality/2017

- Office for National Statistics, Statistical bulletin: Population of the UK by country of birth and nationality: 2018, https://www.ons.gov.uk/peoplepopulationandcommunity/populationan dmigration/internationalmigration/bulletins/ukpopulationbycountryofbir thandnationality $/ 2018$

- Office for National Statistics, Migration Statistics Quarterly Report: July 2018,

https://www.ons.gov.uk/peoplepopulationandcommunity/populationan dmigration/internationalmigration/bulletins/migrationstatisticsquarterlyr eport/july2018revisedfrommaycoveringtheperiodtodecember 2017

- Office for National Statistics, Migration Statistics Quarterly Report: August 2019,

https://www.ons.gov.uk/peoplepopulationandcommunity/populationan dmigration/internationalmigration/bulletins/migrationstatisticsquarterlyr eport/august2019\#table-92674401

Secondary sources: 
- Ragazzi, Francesco. 2009. "Governing diasporas", International Political Sociology. 3(4), pp. 378-397

- Ravenstein, Ernst Georg.1885. "The Laws of Migration", Journal of the Statistical Society of London. Vol. 48. No.2, pp. 167-235

- Sampson, Thomas. 2017. "Brexit: The Economics of International Disintegration", Journal of Economic Perspectives - Volume 31, Number 4, pp. 163-184

- Shaw, Jo. 2016. "Citizenship, Migration and Free Movement in Brexit Britain", German Law Journal, 17(S1), pp. 99-104

- Sinatti, Giulia; Horst, Cindy. 2015. Migrants as agents of development: Diaspora engagement discourse and practice in Europe, Sage, pp. 135-136

- Sjaadstad, Larry. 1962. "The costs and returns of human migration," Journal of Political Economy 70, pp. 80-93

- Todaro, Michael P; Smith Steven. 2015. Economic Development, Pearson

- O'reilly, Karen. 2015. Migration Theories: A Critical Overview, Routledge Handbook of Immigration and Refugee Studies, Oxford: Routledge, pp. 2533

- Østergaard-Nielsen, Eva. 2003. International Migration and Sending Countries: Perceptions, Policies and Transnational Relations, Palgrave Macmillan

- Yuval-Davis, Nira. 2006. "Belonging and the Politics of Belonging", Patterns of Prejudice, 40:3, Routledge, pp. 197-214

Online sources:

- Financial Times, "Net migration to Brexit Britain from EU drops to 5-year low", consulted at: 17.07.2019, available at: https://www.ft.com/content/6198fe42-88d4-11e8-bf9e-8771d5404543

- Politico, "Boris Johnson insists free movement 'will end' October 31", consulted at 25.08.2019, https://www.politico.eu/article/boris-johnsoninsists-free-movement-will-end-october-31/

- Radio Europa Liberă România, "Ministrul pentru romanii de pretutindeni: 9, 7 milioane de români trăiesc în afara granițelor țării, iar 5,6 milioane sunt în diaspora", consulted at 27.07.2019, https://romania.europalibera.org/a/ministrul-pentru-diaspora-9-7- 
milioane-de-romani-traiesc-in-afara-granitelor-tarii-iar-mai-mult-dejumatate-sunt-in-diaspora/30073056.html 